Agriculture, Agribusiness and Biotechnology

Vol.60: e17160304, January-December 2017 http://dx.doi.org/10.1590/1678-4324-2017160304 ISSN 1678-4324 Online Edition

\title{
Effect of nutrients on total lipid content and fatty acids profile of Scenedesmus obliquus
}

\author{
Behrouz Zarei Darki ${ }^{1}{ }^{*}$, Jafar Seyfabadi $^{1}$, Sima Fayazi ${ }^{1}$. \\ ${ }^{I}$ Tarbiat Modares University - Department of Marine Biology, Noor, Mazandaran, Iran.
}

\begin{abstract}
The effect of nutrients on the total lipid content and fatty acid profile of Scenedesmus obliquus isolated from the south coast of the Caspian Sea was evaluated. The nutritional compositions of the media impacted the growth rate and biomass of $S$. obliquus that ranged from $0.175 \mathrm{day}^{-1}$ to $0.209 \mathrm{day}^{-1}$ and $0.92 \mathrm{gr} \cdot \mathrm{l}^{-1}$ to $1.79 \mathrm{gr} \cdot \mathrm{l}^{-1}$, respectively. The alga grew better in the medium which was characterized by higher levels of sodium and trace elements such as Fe, Mn, Mo, and Co and poor in N and P as compared with the other media. The highest level of the total lipid (32\%) and the highest values of saturated fatty acids, in particular palmitic acid also were positively correlated with these nutrients. Peaks in polyunsaturated fatty acids (43.7\%), especially $\alpha$-linolenic acid (28.4\%) were related to $N$ and $P$, but its correlation with $K$ and $M g$ was more evident. The most important factors correlated with high amount of monounsaturated fatty acids were also $N$ and $P$, followed by $K$ and $M g$ to a lesser extent. This study demonstrated that the same algal strain may be a source of different amount of fatty acids, depending on the composition of the culture medium.
\end{abstract}

Key words: monounsaturated fatty acids; polyunsaturated fatty acids; Canonical correspondence analysis; green algae; Caspian Sea

\footnotetext{
*Author for correspondence: zareidarki@modares.ac.ir, zarei@mail.ru
} 


\section{INTRODUCTION}

Many microalgae contain considerable amounts of polar and nonpolar or neutral lipids that play important roles in different consumers ${ }^{1-4}$. Among them, polyunsaturated fatty acids (PUFAs) especially eicosapentaenoic (EPA), docosahexaenoic (DHA), and arachidonic acids (AA) are the most valuable to create significant physiological and biochemical changes in a body, including reducing risk of cardiovascular diseases ${ }^{5-9}$.

Definitely, the total lipid content may vary noticeably among individual species or strains within and between taxonomic groups ${ }^{7}$. In recent years, species of green algae are often considered as a source of essential fatty acids that is necessary not only for improving the organism nutrition, but also for production of biodiesel ${ }^{10-12}$. However, this may not be because green algae naturally contain considerably more lipids than other algal taxa, but rather because many green algae are ubiquitous in diverse natural habitats, can easily be isolated, and generally grow faster than species from other taxonomic groups under laboratory conditions ${ }^{13}$. Among green algae, Scenedesmaceae family is one of the most popular food sources in experiments with herbivorous zooplankton ${ }^{14}$, and also a potential source of lipids that constitute up to $47 \% \mathrm{DW}^{15}$, particularly PUFAs group, including oleic, linoleic, palmitic and alphalinolenic acids ${ }^{16}$. Scenedesmus Meyen is a freshwater and marine genus with 433 known species worldwide ${ }^{17}$, of which 27 species has been reported in aquatic ecosystems of $\operatorname{Iran}^{18}$.

In nature, the cytoplasmic oil droplets are accumulated under stressful environmental conditions, such as high temperature, light intensity and rise in salinity ${ }^{19-22}$. In culture, nutritional composition of the medium has more effects on the total lipid content and fatty acid profile, among which nitrogen, silicon and phosphorus have greater roles ${ }^{20-24}$, followed by iron ${ }^{25-28}$. In 1987, the lipid content and fatty acid composition of Scenedesmus obliquus was determined ${ }^{29}$, but at a later time, the values differed within the species ${ }^{30-32}$. Therefore, the present study focused on whether the nutritional composition could affect the total lipid content and fatty acid profile of S. obliquus that was isolated from the Caspian Sea.

\section{MATERIALS AND METHODS}

\section{The alga strain and growth conditions}

Sampling was carried out in the Nour shore of the Caspian Sea shore near the Department of Marine Biology of Tarbiat Modares University ( $36^{\circ} 35^{\prime} 22^{\prime \prime} \mathrm{N}, 52^{\circ} 02^{\prime}$ $05^{\prime E)}$ by a plankton net with a mesh size of 55 and the Ruthner's bathometer in 2012. S. obliquus was isolated and purified using the agar plates and repeated liquid culture. To obtain a liter of suspension, S. obliquus strain from the stock culture was inoculated into the sterile medium close by the flame, until the transmission coefficient (T) got to $92-93 \%{ }^{33}$. The alga was grown in the growth chamber of Binder model maintaining the light intensity of $60 \mu \mathrm{E} . \mathrm{m}^{-2} \mathrm{~s}^{-1}$ for $0: 24 \mathrm{~h}$ a dark/light cycle and temperature of $25 \pm 0.5{ }^{\circ} \mathrm{C}$ for 31 days. Three media, viz. Trenkenshu, Tamiya and Guillard were used to grow the alga (Table 1).

Table 1 - Nutritional composition of three culture media ${ }^{33-35}$.

\begin{tabular}{|c|c|c|c|c|c|c|c|}
\hline Guillard & & & Tamiya & & & Trenkenshı & \\
\hline $\begin{array}{l}\text { Name } \\
\text { solution }\end{array}$ & Compound & $\begin{array}{l}\text { Required } \\
\text { amount } \\
\left(\mathrm{gr} 1^{1}\right)\end{array}$ & $\begin{array}{l}\text { Name } \\
\text { solution }\end{array}$ & Compound & $\begin{array}{l}\text { Required } \\
\text { amount } \\
\left(\mathrm{gr} \mathrm{l}^{1}{ }^{1}\right)\end{array}$ & Compound & $\begin{array}{l}\text { Require } \\
\text { d } \\
\text { amount } \\
\text { (gr } 1^{1}{ }^{1} \text { ) }\end{array}$ \\
\hline
\end{tabular}


Effect of nutrients on fatty acids profile

\begin{tabular}{|c|c|c|c|c|c|c|c|}
\hline \multirow{4}{*}{$\begin{array}{l}\text { Main } \\
\text { solution }\end{array}$} & NaNO3 & 0.075 & \multirow{11}{*}{$\begin{array}{l}\text { Main } \\
\text { solution }\end{array}$} & $\mathrm{KNO}_{3}$ & 5 & $\mathrm{NaNO}_{3}$ & 1.8 \\
\hline & $\mathrm{NaH}_{2} \mathrm{PO}_{4}$ & 0.005 & & $\mathrm{KH}_{2} \mathrm{PO}_{4} 3 \mathrm{H}_{2} \mathrm{O}$ & 1.25 & $\mathrm{NaH}_{2} \mathrm{PO}_{4} 2 \mathrm{H}_{2} \mathrm{O}$ & 0.3 \\
\hline & $2 \mathrm{H}_{2} \mathrm{O}$ & 0.03 & & $\mathrm{MgSO}_{4} 7 \mathrm{H}_{2} \mathrm{O}$ & 2.5 & $\mathrm{Na}_{2}$ EDTA & 0.037 \\
\hline & $\mathrm{Na}_{2} \mathrm{SiO}_{3} 9 \mathrm{H}_{2} \mathrm{O}$ & & & $\mathrm{Na}_{2}$ EDTA & 0.037 & $\mathrm{FeC}_{6} \mathrm{H}_{5} \mathrm{O}_{7} 7 \mathrm{H}_{2} \mathrm{O}$ & 0.042 \\
\hline \multirow[t]{7}{*}{ Vitamins } & & 0.0005 & & $\mathrm{FeSO}_{4} 7 \mathrm{H}_{2} \mathrm{O}$ & 0.009 & $\mathrm{MnCl}_{2} 4 \mathrm{H}_{2} \mathrm{O}$ & 0.008 \\
\hline & Biotin & 0.00001 & & TES & $1 \mathrm{ml}$ & $\mathrm{Co}\left(\mathrm{NO}_{3}\right)_{2} 6 \mathrm{H}_{2} \mathrm{O}$ & 0.00625 \\
\hline & Thiamine & 0.0005 & & & & $\left(\mathrm{NH}_{4}\right)_{6} \mathrm{Mo}_{7} \mathrm{O}_{24}$ & 0.00183 \\
\hline & B12 & & & & & $4 \mathrm{H}_{2} \mathrm{O}$ & 0.00238 \\
\hline & & & & & & $\mathrm{K}_{2} \mathrm{Cr}_{2}\left(\mathrm{SO}_{4}\right)_{2}$ & 0.00058 \\
\hline & & $1000 \mathrm{ml}$ & & Filtrated & $1000 \mathrm{ml}$ & $24 \mathrm{H}_{2} \mathrm{O}$ & $1000 \mathrm{ml}$ \\
\hline & $\begin{array}{l}\text { Filtrated } \\
\text { seawater }\end{array}$ & & & seawater & & $\begin{array}{l}\mathrm{TiO}_{2} \\
\text { Filtrated seawater }\end{array}$ & \\
\hline \multirow{8}{*}{$\begin{array}{l}\text { Trace } \\
\text { element } \\
\text { solution } \\
\text { (TES) }\end{array}$} & $\mathrm{Na}_{2}$ EDTA & 0.00436 & \multirow{8}{*}{$\begin{array}{l}\text { Trace } \\
\text { element } \\
\text { solution } \\
\text { (TES) }\end{array}$} & $\mathrm{H}_{3} \mathrm{BO}_{3}$ & 2.86 & & \\
\hline & $\mathrm{FeCl}_{3} 6 \mathrm{H}_{2} \mathrm{O}$ & 0.0032 & & $\mathrm{MnCl}_{2} 4 \mathrm{H}_{2} \mathrm{O}$ & 1.81 & & \\
\hline & $\mathrm{MnCl}_{2} 4 \mathrm{H}_{2} \mathrm{O}$ & 0.0002 & & $\mathrm{ZnSO}_{4} 7 \mathrm{H}_{2} \mathrm{O}$ & 0.222 & & \\
\hline & $\mathrm{CuSO}_{4} 5 \mathrm{H}_{2} \mathrm{O}$ & 0.00001 & & $\mathrm{NH}_{4} \mathrm{VO}_{3}$ & 0.023 & & \\
\hline & $\mathrm{ZnSO} 47 \mathrm{H}_{2} \mathrm{O}$ & 0.00002 & & $\mathrm{MoO}_{3}$ & 0.015 or & & \\
\hline & $\mathrm{CoCl}_{2} 6 \mathrm{H}_{2} \mathrm{O}$ & 0.00001 & & $\left(\mathrm{NH}_{4}\right)_{6} \mathrm{Mo}_{7} \mathrm{O}_{24}$ & 0.023 & & \\
\hline & $\mathrm{Na}_{2} \mathrm{MoO}_{4}$ & 0.000000 & & $4 \mathrm{H}_{2} \mathrm{O}$ & & & \\
\hline & $2 \mathrm{H}_{2} \mathrm{O}$ & 6 & & Distilled water & $1000 \mathrm{ml}$ & & \\
\hline
\end{tabular}

\section{Assessment of the microalgae growth}

Cell number was daily counted with a Neubauer hemocytometer using a light microscope in triplicate for each sample and cell density was measured according to the following formula ${ }^{34}$ :

Cell density per milliliter $=$ Total cell counts $\times 10^{4} \times$ Dilution factor

The growth of alga also was monitored by determining the absorbance using a UVVis spectrophotometer at $750 \mathrm{~nm}^{33}$. The biomass values were obtained by the calibration curve of absorbance versus dry weight biomass concentration.

The specific growth rate (GR) of cultured microalgae was calculated by the following equation:

$\mathrm{GR}=\ln (\mathrm{X} 1-\mathrm{X} 2) / \mathrm{t} 2-\mathrm{t} 1$

Where,

$\mathrm{X} 1=$ Biomass concentration at the end of selected time interval,

$\mathrm{X} 2=$ Biomass concentration at the beginning of selected time interval,

$\mathrm{t} 2-\mathrm{t} 1=$ Elapsed time between selected time in the day.

The stationary phase was reached when the absorbance values stabilized, proceeding then to the biomass harvest.

\section{Total lipid and fatty acid analysis}

The total lipid was estimated from dry cells of S. obliquus collected in the stationary phase (it was for each medium on the different days) according to the protocol of Bligh and Dyer ${ }^{36}$. Before the lipid extraction, the samples of $0.05 \pm 0.001 \mathrm{gr} D W$ were fairly soaked in $4 \mathrm{ml}$ of distilled water and were homogenized with a manual homogenizer for one minute. The algal samples were extracted with chloroform: methanol mixture $(2: 1 \mathrm{v} / \mathrm{v})$ and kept for 5 minutes at room temperature. After a fiveminute rest, they were dissolved in a methanol-chloroform-water mixture (MCWM) $(3 / 3 / 1, \mathrm{v} / \mathrm{v} / \mathrm{v})$ and were homogenized; the piston was washed every time with $3.5 \mathrm{ml}$ 
of MCWM. The resulting mixture was incubated for 15 minutes at room temperature, then $5 \mathrm{ml}$ of chloroform was added and the mixture was given 15 minutes rest for lipid extraction. For appearing two phases in the samples, 5 milliliter of distilled water was added and the samples were heavily shaken. The lipid fractions were separated in a clean pre-weighed vial (first wt) and the solvent was evaporated using a rotary evaporator. The weight of the vial was again recorded (second wt). Total lipid was calculated by subtracting first wt from second wt. The final organic phase was dried under nitrogen.

Preparation of fatty acid methyl ester from the total lipid was performed according to Radwan ${ }^{37}$. All analyses for identification of fatty acid contents were performed using gas chromatography (Varian CP-3800 model).

\section{Statistical analysis}

All experiments were repeated three times independently, and the data were recorded as the mean. The statistical analyses were performed using the software Statistical Program for Social Sciences 17.0. A one-way ANOVA and Duncan test were used to evaluate the differences among the treatments. Canonical-correlation analysis (CCA) and Pearson's coefficient were used to determine relationships among the nutritive composition of a culture medium and amount of total lipid content and fatty acid profile.

\section{RESULTS}

Nutrient availability had a significant impact on growth of the microalga and broad effects on its lipid and fatty acid composition. The effect of the nutritional compounds as three investigated media on the growth of was recorded by way of cell count (cell number $1^{-1}$ ) and optical density (OD) every day, both of which showed quite similar curves (Figures 1 and 2). The algal cell growth was greatly affected in Trenkenshu and Tamyia media. In Trenkenshu medium, the maximum cell count $\left(17 \times 10^{6} \mathrm{cell} \cdot \mathrm{ml}^{-1}\right)$ and OD $\left(1.26\right.$ at $\left.\mathrm{A}_{750}\right)$ were recorded on the $25^{\text {th }}$ day. The lowest cell number was recorded in Guillard medium $\left(\max .14 \times 10^{6} \mathrm{cell} \cdot \mathrm{ml}^{-1}\right.$ on the $30^{\text {th }}$ day). In Trenkenshu medium, the lag phase lasted less than in the other media that points to more quickly culture adaption. The exponential phase started at $0.2 \mathrm{OD}_{750}$ and continued to $1.2 \mathrm{OD}_{750}$. The longest onset of the stationary phase was observed in Guillard medium on $31^{\text {th }}$ day. The nutritional compositions of the media had markedly impacted the growth rate and biomass of S. obliquus (Figures 3 and 4). The slowest growth rate $\left(0.175 \mathrm{day}^{-1}\right)$ and biomass value $\left(0.92 \mathrm{gr} \cdot \mathrm{l}^{-1}\right)$ were recorded in Guillard medium, while the maximum growth rate $\left(0.209\right.$ day $\left.^{-1}\right)$ and biomass $(1.79$ $\mathrm{gr} \cdot \mathrm{l}^{-1}$ ) were observed in Trenkenshu medium.

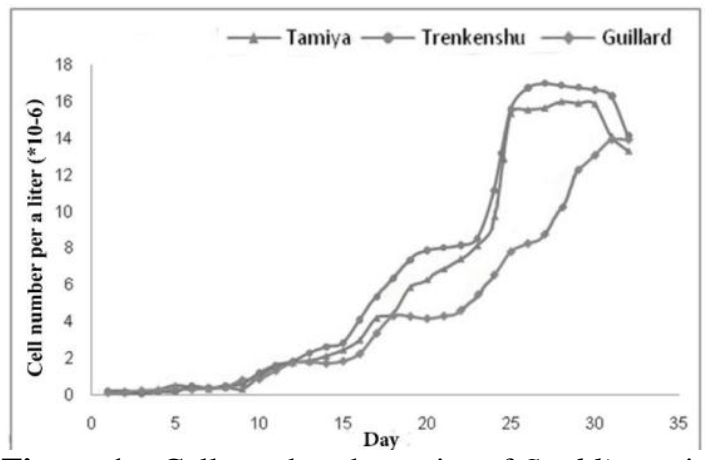

Figure 1 - Cell number dynamics of $S$. obliquus in three culture media 
Effect of nutrients on fatty acids profile

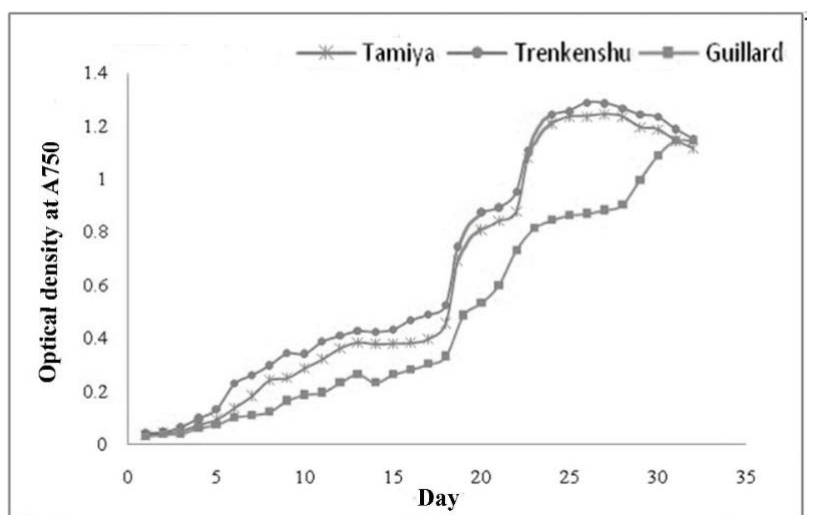

Figure 2 - Optical density dynamics of $S$. obliquus growth in three culture media

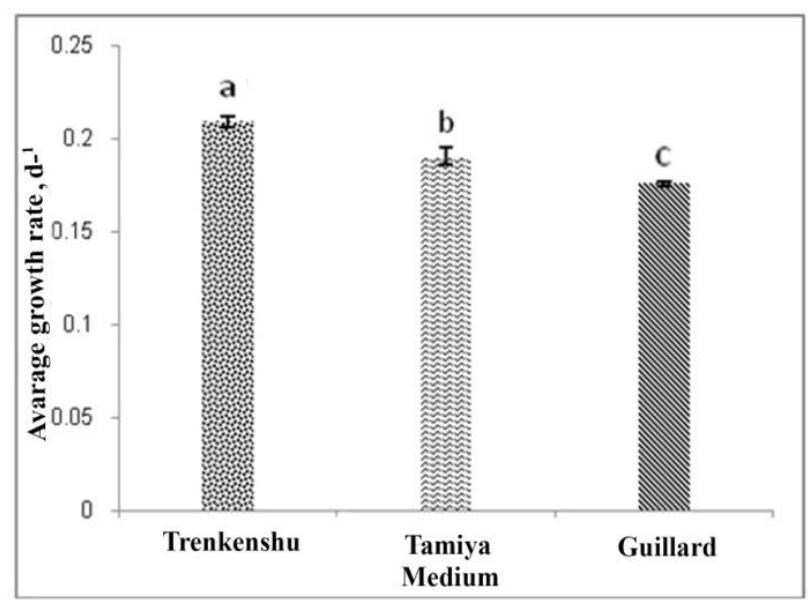

Figure 3 - Specific growth rate of $S$. obliquus in three culture media

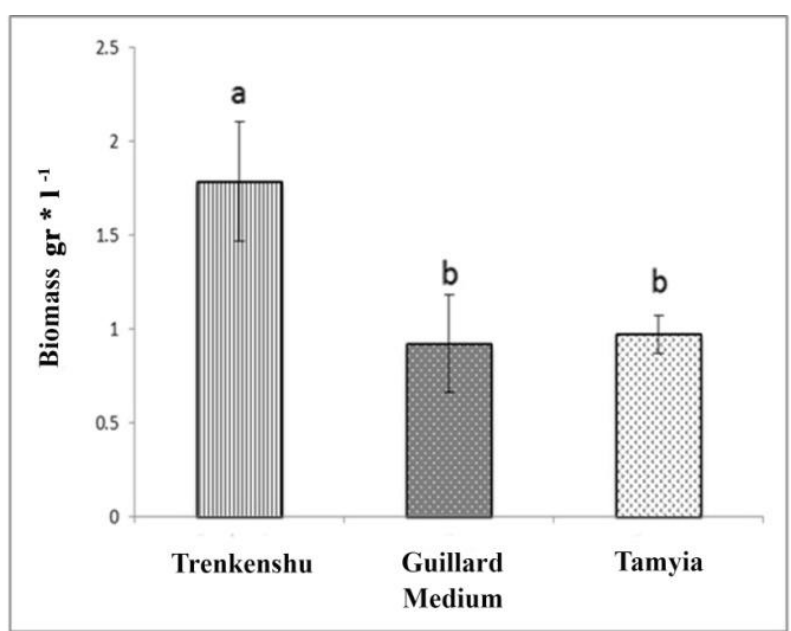

Figure 4 - Biomass of $S$. obliquus culture in three culture media

The highest total lipid content (32\% DW) was observed inTrenkenshu medium (Table 2), which was significantly $(\mathrm{p}<0.05)$ higher than Tamiya $(24 \% \mathrm{DW})$ and Guillard $(21 \%)$ media, but no significant difference $\mathrm{p}>0.05)$ was observed between the latter two media. The highest level of SFAs (45.7\%) was observed in Trenkenshu medium which was significantly different from the other two media $(p<0.05)$, while the highest level of MUFAs (47.6\%) was recorded in Guillard medium which was significantly different from the other two media $(\mathrm{p}<0.05)$. The highest percentage of PUFAs $(43.7 \%)$ was recorded in Tamyia medium, which was significantly different 
from the other two media $(\mathrm{p}<0.05)$. The fatty acids profile of $S$. obliquus also varied according to medium (Table 2). Being the most common saturated fatty acid in living organisms, palmitic acid (C16:0) was also the main SFA in all the three media. Elaidic acid, the trans isomer of oleic acid (C18:1 n-9 trans), was the most important in MUFAs ranging 11.8-39.2. Moreover, cetoleic acid (C22:1n11) showed quite high value $(11.8 \%)$ in Trenkenshu medium. Among PUFAs, ALA was the dominant fatty acid, for which Tamyia medium was a better source. It is interesting to note that lauric and arachidic acids with a 12- and 20-carbon atom chain, respectively, were only quantified in Trenkenshu medium.

Table 2 - Fatty acid profile of S. obliquus in three investigated media. Data are given as $\mathrm{mg} \mathrm{g}^{-1}$ of dry weight

\begin{tabular}{llll}
\hline \multirow{2}{*}{ Fatty acid* } & Medium & & Tamiya \\
\cline { 2 - 4 } SFA & Trenkenshu & Guillard & \\
C12:0 & 4.0 & & - \\
& & - & \\
C14:0 & 1.6 & 1.7 & 4.7 \\
C15:0 & 2.7 & 1.5 & 4.2 \\
C16:0 & 26.7 & 21.2 & 14.0 \\
C17:0 & - & 0.2 & - \\
C18:0 & 7.9 & 1.3 & 9.3 \\
C20:0 & 2.8 & - & - \\
Sum SFAs & $\mathbf{4 5 . 7}$ & $\mathbf{2 5 . 9}$ & $\mathbf{3 2 . 2}$ \\
MUFA & & & \\
C16:1n7 & 2 & 2.8 & 3.3 \\
C17:1 & 3.3 & 4.4 & 3.7 \\
C18:1n9 trans & 12.1 & 39.2 & 11.8 \\
C18:1n9 cis & - & 0.1 & 2.6 \\
C22:1n11 & 11.8 & 1.1 & - \\
Sum MUFAs & $\mathbf{2 9 . 2}$ & $\mathbf{4 7 . 6}$ & $\mathbf{2 1 . 4}$ \\
PUFA & & & \\
C18:2n6 trans & 8.3 & 5.5 & 9.3 \\
C18:2n6 cis & - & 10.2 & 1.8 \\
C18:3n3 & 16.7 & 7.4 & 28.4 \\
C18:3n6 & - & 2.4 & 4.2 \\
Sum PUFAs & $\mathbf{2 5 . 0}$ & $\mathbf{2 5 . 5}$ & $\mathbf{4 3 . 7}$ \\
Total FA & $\mathbf{9 9 . 9}$ & $\mathbf{9 9 . 0}$ & $\mathbf{9 7 . 3}$ \\
Total lipid** & $\mathbf{3 2 . 3}$ & $\mathbf{2 1 . 0}$ & $\mathbf{2 4 . 3}$ \\
SFA/MUFA/PUFA*** & $\mathbf{1 . 8} / 1.2 / 1$ & $1 / 1.9 / 1$ & $1.5 / 1 / 2$ \\
\hline
\end{tabular}

*Fatty acid as a percentage of the total fatty acids mixture

**Total lipids as a percentage of dry weight

***SFA/MUFA/PUFA ratio of saturated fatty acids to monounsaturated and polyunsaturated fatty acids

Based on the CCA, eigenvalues of axes $1(\lambda=0.463)$ and $2(\lambda=0.063)$ explained $88.0 \%$ and $12.0 \%$ of the relation between fatty acids and nutrient data, respectively (Fig. 5, Table 3). The ranks of the nutrition variables contributing to this model were (1) sodium, cobalt and molybdenum, (2) potassium and magnesium, (3) manganese, (4) iron, (5) PUFA, C14:0, C18:1n9c, (6) C15:0, C16:0, C18:3n3, (7) C18:3n6 and C16:1n7. 
Effect of nutrients on fatty acids profile

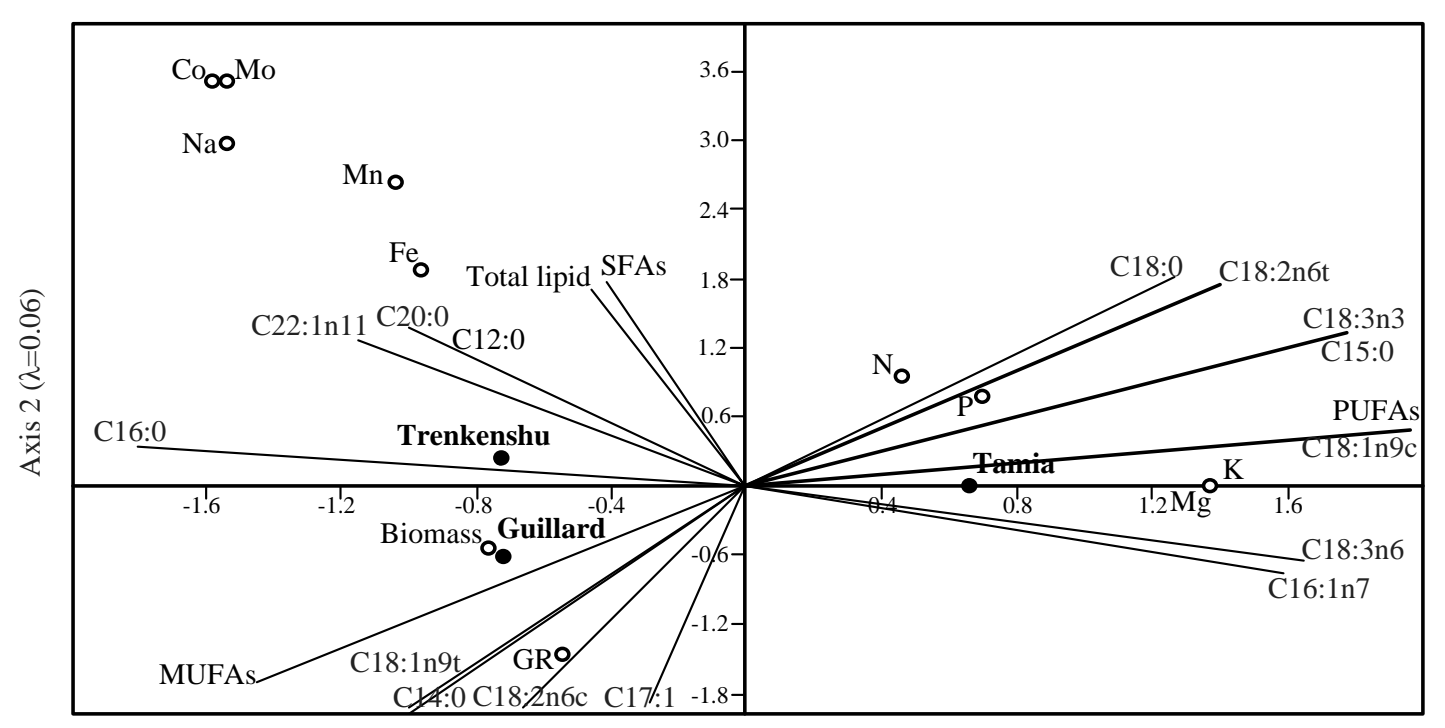

Axis $1 \quad(\lambda=0.46)$

Figure 5 - Canonical correspondence analysis (CCA) biplots showing the relationships between media, nutrients growth parameters, total lipid and fatty acids.

Table 3 - Correlations of nutrients, growth parameters and fatty acids with axes from reference site data. $\lambda$ represents eigenvalue for each axes.

\begin{tabular}{lll}
\hline Variables & Axes $\mathbf{1}$ & Axes 2 \\
& $\boldsymbol{\lambda}=\mathbf{0 . 4 6}$ & $\boldsymbol{\lambda}=\mathbf{0 , 0 6}$ \\
\hline GR & -0.55 & -1.49 \\
Biomass & -0.76 & -0.56 \\
N & 0.46 & 0.95 \\
P & 0.70 & 0.77 \\
Na & $\mathbf{- 1 . 5 4}$ & 2.97 \\
K & $\mathbf{1 . 3 7}$ & 0.01 \\
Mg & $\mathbf{1 . 3 7}$ & 0.01 \\
Fe & $\mathbf{- 0 . 9 6}$ & 1.87 \\
Mn & $\mathbf{- 1 . 0 4}$ & 2.64 \\
Mo & $\mathbf{- 1 . 5 5}$ & 3.51 \\
Co & $\mathbf{- 1 . 5 8}$ & 3.52 \\
SFA & -0.21 & 0.89 \\
PUFA & $\mathbf{0 . 9 9}$ & 0.25 \\
MUFA & -0.73 & -0.86 \\
C12:0 & -0.50 & 0.70 \\
C14:0 & $\mathbf{0 . 9 9}$ & 0.24 \\
C15:0 & $\mathbf{0 . 8 9}$ & 0.69 \\
C16:0 & $\mathbf{- 0 . 9 0}$ & 0.17 \\
C17:0 & -0.50 & -0.97 \\
C18:0 & 0.63 & 0.91 \\
C20:0 & -0.50 & 0.70 \\
C16:1n7 & 0.79 & -0.37 \\
C17:1 & -0.15 & -0.99 \\
C18:1n9t & -0.50 & -0.97 \\
C18:1n9c & $\mathbf{0 . 9 9}$ & 0.24 \\
C22:1n11 & -0.57 & 0.64 \\
C18:2n6t & 0.70 & 0.87 \\
C18:2n6c & -0.35 & -0.99 \\
C18:3n3 & $\mathbf{0 . 9 0}$ & 0.67 \\
C18:3n6 & 0.82 & -0.33 \\
\hline
\end{tabular}

GR: growth rate; significant coefficients shown in bold. 
The total lipid and SFA were correlated with sodium, potassium, magnesium, manganese, molybdenum and cobalt while MUFA and PUFA had positive correlation with nitrogen and phosphorus (Fig. 5, Table 3). Furthermore, PUFA depended strongly on potassium and magnesium. The main fatty acids such as C16:0 and $\mathrm{C} 18: \ln 9 \mathrm{t}$ were correlated with potassium, magnesium, sodium and nitrogen, phosphorus, respectively. ALA (C18:3n3) was associated strongly with nitrogen, phosphorus and less with potassium and magnesium.

\section{DISCUSSION}

The quantity and quality of fatty acids content as well as the entire biochemical composition varies in response to environmental conditions ${ }^{8,20,24,25,38,39}$. Particularly, under unfavorable environmental or stress conditions for growth, such as salinity, temperature, $\mathrm{pH}$, and nutrient levels, many algae alter their lipid biosynthetic pathways towards the formation and accumulation of neutral lipids to control intracellular stress ${ }^{13,40}$. Finding the appropriate conditions to stimulate the synthesis of different fatty acids of interest is crucial for developing an efficient biological production process.

The present research showed significant differences in total lipid and fatty acid profile for the same strain of $S$. obliquus cultivated in three different media (Fig. 5 and Table 3).

Table 4 - Results from Pearson's correlation between total lipid, SFA, PUFA, MUFA and nutritional variables

\begin{tabular}{|c|c|c|c|c|c|c|c|c|c|c|c|}
\hline \multirow{2}{*}{ Fatty acid } & \multicolumn{11}{|c|}{ Nutrients } \\
\hline & GR & B & $\mathbf{N}^{-}$ & $\mathbf{P}^{-}$ & $\mathrm{Na}^{+}$ & $\mathbf{K}^{+}$ & $\mathbf{M g}^{+}$ & $\mathbf{F e}^{+}$ & $\mathbf{M n}^{+}$ & $\mathrm{Mo}^{+}$ & $\mathrm{Co}^{+}$ \\
\hline SFA & 0.99* & 0.97 & 0.22 & 0.08 & 0.94 & \begin{tabular}{|c|}
-0.21 \\
\end{tabular} & -0.21 & 0.99 & 0.99 & $\begin{array}{l}0.96 \\
\end{array}$ & 0.96 \\
\hline PUFA & 0.09 & -0.48 & 0.90 & 0.95 & $-0,55$ & 1.00 & 1.00 & -0.35 & -0.35 & -0.51 & -0.52 \\
\hline MUFA & 0.63 & -0.28 & 0.95 & 0.90 & -0.20 & -0.73 & -0.73 & -0.41 & -0.41 & -0.23 & -0.23 \\
\hline Total lip & .99 & 0.97 & 0.20 & 0.50 & 0.95 & $-0,23$ & -0.23 & 0.99 & 0.99 & 0.95 & 0.95 \\
\hline C12:0 & .90 & 0.99 & -0.09 & -0.23 & 1.00 & -0.50 & -0.50 & 0.98 & 0.98 & 1.00 & 1.00 \\
\hline C14:0 & 0.10 & -0.48 & 0.89 & 0.95 & -0.55 & 1.00 & 1.00 & -0.35 & -0.35 & -0.52 & -0.53 \\
\hline C1 & 38 & -0.10 & 1.00 & 0.98 & -0.09 & 0.8 & 0.89 & 0.13 & 0.13 & -0.06 & -0.07 \\
\hline C1C & .50 & 0.80 & -0.64 & -0.75 & 0.84 & -0.90 & -0.90 & 0.70 & 0.70 & 0.82 & 0.83 \\
\hline $\mathrm{C17}$ & 0.83 & -0.54 & -0.82 & -0.72 & -0.47 & -0.50 & -0.50 & -0.66 & -0.66 & -0.51 & -0.50 \\
\hline C18:0 & 0.73 & 0.40 & 0.90 & 0.83 & 0.32 & 0.64 & 0.64 & 0.52 & 0.53 & 0.36 & 0.35 \\
\hline C20 & 0.90 & 0.99 & -0.09 & -0.24 & 1.00 & -0.50 & -0.50 & 0.98 & 0.98 & 1.00 & 1.00 \\
\hline C16 & -0.66 & -0.90 & 0.46 & 0.58 & -0.93 & 0.79 & 0.79 & -0.83 & -0.83 & -0.92 & -0.93 \\
\hline C17:1 & -0.97 & -0.80 & -0.55 & -0.42 & -0.75 & -0.15 & -0.15 & -0.88 & -0.88 & -0.78 & -0.78 \\
\hline C18 & -0.82 & -0.53 & -0.82 & -0.73 & -0.46 & -0.50 & -0.50 & -0.64 & -0.65 & -0.49 & -0.49 \\
\hline C18 & -0.10 & -0.48 & 0.89 & 0.95 & -0.55 & 0.99 & 0.99 & -0.35 & -0.35 & -0.52 & -0.53 \\
\hline $\mathrm{C} 22$ & 0.85 & 0.99 & -0.17 & -0.31 & 0.99 & -0.57 & -0.57 & 0.96 & 0.96 & 0.99 & 1.00 \\
\hline C18 & 0.66 & 0.31 & 0.93 & 0.8 & 0.23 & 0.70 & 0.70 & 0.44 & 0.45 & .027 & 0.26 \\
\hline & -0.91 & -0.67 & -0.71 & -0.59 & -0.61 & -0.35 & -0.35 & -0.77 & -0.77 & -0.64 & -0.64 \\
\hline & 38 & -0.02 & & 0.9 & -0.09 & & $\mathbf{0 . 8 9}$ & 0. & 0.13 & -0.06 & -0.07 \\
\hline C18:3n6 & -0.62 & -0.88 & 0.51 & 0.62 & -0.91 & -0.82 & -0.82 & -0.80 & -0.80 & -0.90 & -0.91 \\
\hline
\end{tabular}

*negative and positive correlating values are shown in bold

The fatty acids content as well as the ratio between unsaturated and saturated fatty acids is an important parameter for determination of algae value. SFAs were found to increase by increasing the iron amount in Nannochloropsis oculata ${ }^{20}$. In Dunaliella tertiolecta and Stephanodiscus minutulus, changes of the SFA's values were directly related to changes in the amount of nitrogen ${ }^{24}$.In the present study, SFAs showed significantly positive correlationship with manganese and iron first of 
all, then sodium which were sufficiently present in Trenkenshu medium (Table 3 and Figure 5).In addition, trace elements such as molybdenum and cobalt are the important nutritional variables for obtaining high SFAs and total lipid. Dou et al. ${ }^{27}$ also found that the addition of $\mathrm{Fe}^{3+}, \mathrm{Zn}^{2+}, \mathrm{Mn}^{2+}, \mathrm{Mo}^{6+}$, and EDTA can increase the lipid productivity. S. obliquus cultivated in Trenkenshu medium can be used for biofuel because quite high content of palmitic acid obtained in this medium is desirable for good quality biodiesel ${ }^{12}$. Furthermore, palmitic, lauric and myristic acids are not good substances in nutrition of living organisms because they are responsible for raising bad cholesterol levels in blood serum ${ }^{41}$. According to Napolitano et al. ${ }^{42}$, SFAs may play a double role: as a store of saturated fatty acids to be used as a source of energy and as a store of PUFAs required for phospholipid synthesis to various membrane structures or to be integrated in several metabolic processes.

PUFAs are one of the most nutritionally important and essential fatty acids because they are key nutrients in animal nutrition, and the most algae are rich in these acids 43. Nitrogen and phosphate are two important macronutrients for phospholipids because nitrogen and phosphorus starvation shifts the lipid metabolism from membrane lipid synthesis to neutral lipid storage ${ }^{39,44-46}$. Results of the present study also showed clearly that peaks in PUFAs are related to nitrogen and phosphorus, but its correlation with potassium and magnesium was more evident. In Tamiya medium, the most dominant fatty acid ALA also was related to nitrogen, phosphorus, potassium and magnesium. The ratio between PUFA and SFA content observed in Tamiya medium can be considered as nutritional value of $S$. obliquus cultivated in this medium because the higher value of $\mathrm{P} / \mathrm{S}$ index means a smaller deposition of lipids in the body ${ }^{47}$.

There are reports that amount of MUFAs goes up due to the reduction of nitrogen in the culture medium ${ }^{20,23}$. The potential relationship between phosphorus and amount of MUFAs have beenshown intwo microalgae Phaeodactylum tricornutum and Dunaliella tertiolecta ${ }^{48}$ and the yellow-green alga, Monodus subterraneus ${ }^{49}$, in which reduced phosphorus in medium had impacted MUFAs. By analyzing the changes in fatty acids composition of several algal species at different concentrations of nitrogen and silica, Shifrin and Chisholm ${ }^{50}$ showed increase in MUFAs as the result of nitrogen limitation. In our experiment, the most important factors correlated with high amount of MUFAs were also nitrogen and phosphorus, followed by potassium and magnesium to a lesser extent. Limitation of these parameters caused growth delay and an accumulation of fatty acids forming MUFAs especially elaidic acid.

\section{CONCLUSIONS}

Based on the results of the present study, it can be concluded that the same algal strain may be a source of different fatty acids, depending on the nutritive composition of the culture medium. Sodium, iron, cobalt and molybdenum impacted on the growth rate, SFAs in particular palmitic acid, and, as the result, the total lipid content in the green alga S. obliquus. The highest amount of PUFAs and oleic acid were related to potassium and magnesium and less nitrogen and phosphorus. The highest amount of MUFAs, especially ALA were obtained at limitation of nitrogen and phosphorus caused growth delay and an accumulation of fatty acids forming MUFAs especially elaidic acid. Thus, the knowledge about stimulation of the synthesis of different fatty acids may be used for algal cultivation with the different purposes. 


\section{ACKNOWLEDGMENTS}

The authors express their gratitude to Tarbiat Modares University for providing funding and research facilities. We also thank laboratory assistant of Faculty of Marine Sciences for help.

\section{REFERENCES}

1 - Renaud SM, Parry DL, Luong-Van T, Kuo C, Padovan A, Sammy N. Effect of light intensity on the proximate biochemical and fatty acid composition of Isochrysis sp. and Nannochloropsis oculata for use in tropical aquaculture. J Appl Phycol. 1991; 3: 43-53.

2 - Richmond A, editor. Handbook of microalgal culture: Biotechnology and Applied Phycology. Wiley-Blackwell; 2003.

3 - Gopinathan CP. Differential growth rates of microalgae in various culture media. Indian J Fish. 1986; 33: 450-456.

4 - Wen ZY, Chen F. Heterotrophic production of eicosapentaenoic acid by microalgae. Biotechnol Adv. 2003; 21 (4): 273-294.

5 - Napolitano GE. Fatty acids as trophic and chemical markers in freshwater ecosystems. In: Arts MT, Wainman BC, editors. Lipids in Freshwater Ecosystems. Springer-Verlag New York; 1999, p. 21-44.

6 - Bigogno Ch, Khozin-Goldberga I, Boussibaa S, Vonshaka A, Cohen Z. Lipid and fatty acid composition of the green oleaginous alga Parietochloris incisa, the richest plant source of arachidonic acid. Phytochemistry. 2002; 60: 497-503.

7 - Patil V, Källqvist T, Olsen E, Vogt G, Gislerød HR. Fatty acid composition of 12 microalgae for possible use in aquaculture feed. Aquacult Int. 2007; 15:1-9. doi:10.1007/s10499-006-9060-3.

8 - Nomura M, Kamogawa H, Susanto E, Kawagoe C, Yasui H, Saga N, Hosokawa M, Miyashita K. Seasonal variations of total lipids, fatty acid composition, and fucoxanthin contents of Sargassum horneri (Turner) and Cystoseira hakodatensis (Yendo) from the northern seashore of Japan. J Appl Phycol. 2013; 25(4): 1159-1169.

9 - Le HD, Meisel JA, De Meijer VE, Gura KM, Puder M. The essentiality of arachidonic acid and docosahexaenoic acid. Prostag Leukotr Ess. 2009; 81(2): 165-170.

10 - Deng X, Li Y and Fei X. Microalgae: A promising feedstock for biodiesel. Afr J Microbiol Res. 2009; 3 (13): 1008-1014.

11 - Mata TM, Martinsc AA, Caetano NS. Microalgae for biodiesel production and other applications: A review. Renew Sust Energ Rev. 2010; 14: 217-232.

12 - Mandal S, Mallick N. Biodiesel production by the green microalga Scenedesmus obliquus in a Recirculatory Aquaculture System. Appl. Environ. Microbiol. 2012; 78(16): 5929-5934. doi:10.1128/AEM.00610-12.

13 - Hu Q, Sommerfeld M, Jarvis E, Ghirardi M, Posewitz M, Seibert M and Darzins A, Microalgal triacylglycerols as feedstocks for biofuel production: perspectives and advances. Plant J. 2008; 54: 621-639. doi: 10.1111/j.1365-313X.2008.03492.x.

14 - Lürling M, De Lange HJ, Van Donk E. Changes in food quality of the green alga Scenedesmus induced by Daphnia infochemicals: biochemical composition and morphology. Freshwater Biol. 1997; 38: 619-628. doi: 10.1046/j.1365-2427.1997.00225.x.

15 - Ferrigo D, Galla G, Sforza E, Morosinotto T, Barcaccia G, Berrini CC. Biochemical characterization and genetic identity of an oil-rich Acutodesmus obliquus isolate. J Appl Phycol. 2015; 27(1): 149-161. doi: 10.1007/s10811-014-0315-5.

16 - Goswami R, Kalita MK. Scenedesmus dimorphus and Scenedesmus quadricauda: Two potent indigenous microalgae strains for biomass production and CO mitigation a study on their growth behavior and lipid productivity under different concentration of urea as nitrogen source. J Algal Biomass Utilization. 2011; 2(4): 42-49.

17 - Guiry MD, Guiry GM. AlgaeBase. World-wide electronic publication, National University of Ireland, Galway; (2015). Available from: http://www.algaebase.org.

18 - Zarei Darki B. Features of algae distribution of Order Sphaeropleales (Chlorophyceae) in different water bodies of Iran. Int J Algae. 2012; 14(4): 323-330. 
Effect of nutrients on fatty acids profile

19 - Gushina IA, Harwood JL. Algal lipids and effect on the environment on their biochemistry. In: Arts MT, Brett MT, Kainz M, editors. Lipids in Aquatic Ecosystems. Springer-Verlag New York; 2009, p. 1-24. doi:10.1007/978-0-387-89366-2_1.

20 - Lynn SG, Kilham SS, Kreeger DA, Interlandi SJ. Effect of nutrient availability on the biochemical and elemental stoichiometry in the freshwater diatom Stephanodiscus minutulus (Bacillariophyceae). J Phycol. 2000; 36 (3): 510-522.

21 - Solovchenko AE. Physiological Role of Neutral Lipid Accumulation in Eukaryotic Microalgae under Stresses. Russ J Plant Physiol. 2012; 59 (2): 192-202.

22 - Xia L, Yang H, He Q, Hu Ch. Physiological responses of freshwater oleaginous microalgae Desmodesmus sp. NMX451 under nitrogen deficiency and alkaline pH-induced lipid accumulation. J Appl Phycol. 2014; 27(2): 649-659.

23 - Lopez Alonso D, Belarbi EH, Fernandez Sevilla JM, Ruiz RJ, Grima EM. Acyl lipid composition variation related to culture age and nitrogen concentration in continuous culture of the microalga Phaeodactylum tricornutum. Phytochemistry. 2000; 54(5): 461-471.

24 - Chen M, Tang H, Ma H, Holland TC, Simon NKY, Salley SO. Effect of nutrients on growth and lipid accumulation in the green algae Dunaliella tertiolecta. Bioresource Technol. 2011; 102: 1649-1655.

25 - Liu ZY, Wang C, Zhou BC. Effect of iron on growth and lipid accumulation in Chlorella vulgaris. Bioresource Technol. 2008; 99 (11): 4717-4722.

26 - Gonzalez PM, Piloni NE, Puntarulo S. Iron overload and lipid peroxidation in biological systems. School of Pharmacy and Biochemistry, University of Buenos Aires; 2012, p. 89108.

27 - Dou X, Lu XH, Lu MZ, Yu LS, Xue R, Ji JB. The effects of trace elements on the lipid productivity and fatty acid composition of Nannochloropis oculata. J Renew Energy. 2013; 1-6. Available from: http://dx.doi.org/10.1155/2013/671545.

28 - Mata TM, Almeida R, Caetano NS. Effect of the culture nutrients on the biomass and lipid productivities of microalgae Dunaliella tertiolecta. Chem Eng Tranceact. 2013; 32: 973-978.

29 - Choi KJ, Nakhost Z, Barzana E, Karel M. Lipid content and fatty acid composition of green algae Scenedesmus obliquus grown in a constant cell density apparatus. Food Biotechnol. 1987; 1(1): 117-28.

30 - Makulla A. Fatty acid composition of Scenedesmus obliquus: Correlation to dilution rates. Limnologica. 2000; 30: 162-168.

31 - Radmann EM, Costa JAV. Lipid content and fatty acids composition variation of microalgae exposed to CO2, SO2 and NO. Quím. Nova. 2008; 31(7). http://dx.doi.org/10.1590/S0100-40422008000700002.

32 - Salama ES, Kim HC, Abou-Shanab RAI, Ji MK, Oh YK, Kim SH, Jeon BH. Biomass, lipid content, and fatty acid composition of freshwater Chlamydomonas mexicana and Scenedesmus obliquus grown under salt stress. Bioprocess Biosystems Eng. 2013; 36 (6): 827-833.

33 - Trenkenshu RP, Borovkov AB, Lelekov AS. Standardized laboratory setting to study the lower phototrophs. Sevastopol; 2009. Russian.

34 - Guillard RRL. Division rates. In: Stein JR, editors. Handbook of phycological methods, Cambridge University Press, Cambridge; 1973, p. $289-312$.

35 - Kilham SS, Kreeger DA, Lynn SG, Goulden CE. COMBO: a defined freshwater culture medium for algae and zooplankton. Hydrobiologia. 1998; 337(4): 147-159.

36 - Bligh EG, Dyer WJ. A rapid method for total lipid extraction and purification. Can J Biochem Physiol. 1959; 37: 911-917.

37 - Radwan SS. Sources of C20 polyunsaturated of fatty acids for use. Appl. Microbiol Biotechnol. 1978; 35: 421-430.

38 - Zhila NO, Kalacheva GS, Volova TG. Effect of salinity on the biochemical composition of the alga Botryococcus braunii Kütz IPPAS H-252. J Appl Phycol. 2011; 23(1): 47-52. doi: 10.1007/s10811-010-9532-8.

39 - Juneja A, Ruben Cm, Murthy Gs. Effects of environmental factors and nutrient availability on the biochemical composition of algae for biofuels production: A review. Energies. 2013; 6: 4607-4638. doi: 10.3390/en6094607. 
40 - El-Kassas HY. Corrigendum to "Growth and fatty acid profile of the marine microalga Picochlorum sp. grown under nutrient stress conditions. Egyp J Aquatic Resear. 2014; 39: 233-239.

41 - Tholstrup T, Marckmann P, Jespersen J, Vessby B, Jart A and Sandström B. Effect on Blood Lipids, Coagulation and Fibrinolysis of a Fat High in Myristic Acid and a Fat High in Palmitic Acid. Am. J. Clin. Nutr. 1994; 59: 371-377.

42 - Napolitano GE, Ratnayake WMN, Ackman RG. Fatty acid components of larval Ostrea edulis (L.) importance of triacylglycerols as fatty acid reserve. Comp Biochem Physiol. 1988; 90B: 875-883.

43 - Brown MR, Jeffrey SW, Volkman JK, Dunstan GA. Nutritional properties of microalgae for mariculture. Aquaculture. 1997; 151: 315-331.

44 - Solovchenko AE, Khozin-Goldberg I, Didi-Cohen S, Cohen Z, Merzlyak MN. Effects of light intensity and nitrogen starvation on growth, total fatty acids and arachidonic acid in the green microalga Parietochloris incisa. J Appl Phycol. 2008; 20: 245-251. doi: 10.1007/s10811-007-9233-0.

45 - Naderi Farsani M, Meshkiniy S, Manaffar R, Asal Pishe Z. Response of growth, protein and fatty acid content of Desmodesmus cuneatus to the repletion and depletion of nitrogen. Biolog J Microorg. 2015; 3(12): 59-68.

46 - Ruiz-Domínguez MC, Vaquero I, Obregón V, De La Morena B, Vílchez C, Vega JM. Lipid accumulation and antioxidant activity in the eukaryotic acidophilic microalga Coccomyxa sp. (strain onubensis) under nutrient starvation. J Appl Phycol. 2015; 27(3): 1099-1108.

47 - Lawton CL, Delargry HJ, Brockman J, Simith RC and Blundell JE. The degree of saturation of fatty acids influences in post ingestive satiety. Brit J Nutr. 2000; 83 (5): 473 482.

48 - Siron R, Giusti G, Berland B. Changes in the fatty acid composition of Phaeodactylum tricornutum and Dunaliella tertiolecta during growth and under phosphorus deficiency. Mar Ecol-Prog Ser. 1989; 55: 95-100.

49 - Khozin-Goldberg I, Cohen Z. The effect of phosphate starvation on the lipid and fatty acid composition of the freshwater eustigmatophyte Monodus subterraneus. Phytochemistry. 2006; 67(7): 696-701.

50 - Shifrin NS, Chisholm SW. Phytoplankton lipids: interspecific differences and effects of nitrate, silicate and light-dark cycles. J Phycol. 1981; 17: 374-384. 